\title{
Optimasi Arus Dan Tegangan Pada Alat Anodizing Portable
}

\author{
Sugeng Purwanto'; Muhammad Imbarothur Mowaviq²; Andi Junaidi ${ }^{3}$ \\ Sekolah Tinggi Teknik PLN \\ ${ }^{1}$ sugeng.purwanto@sttpln.ac.id
}

\begin{abstract}
Anodizing process is a process that aims to strengthen the natural protective layer of metals so that the metal becomes a material that is resistant to rust and scratch by using electrolyte solutions and strong DC currents that help the occurrence of chemical reactions. The anodizing process is strongly influenced by current and voltage, the greater the current and voltage, the thicker the oxide layer that occurs on the aluminum surface and the hardness (hardness) will also increase so that the material becomes rust resistant, scratch resistant and if given an organic coating easy to fade or peel off. Optimization of current and voltage on portable anodizing devices will add value to the quality (quality value) of these materials.
\end{abstract}

Keywords: Anodizing, Organic Coating, Electrolytic Solution, Optimization

\begin{abstract}
ABSTRAK
Proses anodizing merupakan suatu proses yang bertujuan untuk mempertebal lapisan protektif alami pada logam sehingga logam tersebut menjadi bahan yang tahan terhadap karat dan tahan gores dengan menggunakan larutan elektrolit dan kuat arus DC yang membantu terjadinya reaksi kimia. Proses anodizing sangat dipengaruhi oleh arus dan tegangan, semakin besar arus dan tegangan maka akan semakin tebal lapisan oksida yang terjadi di permukaan aluminium dan kekerasannya (hardness) juga akan meningkat sehingga bahan menjadi tahan karat, tahan gores dan jika diberikan pewarna (organic coating) tidak mudah pudar atau terkelupas. Optimasi arus dan tegangan pada alat anodizing portable akan menambah nilai kualitas (quality value) dari bahan tersebut.
\end{abstract}

Kata kunci: Anodizing, Organic Coating, Larutan Elektrolit, Optimasi 


\section{PENDAHULUAN}

Pada masa yang akan datang, peranan aluminium dalam industri logam sangat penting karena mempunyai keunggulan sifat mekanik dan kimianya dibandingkan dengan logam lain, antara lain ringan sehingga dapat menekan konsumsi energi, kuat terhadap beban berat, tahan terhadap korosi, ketersediaan yang cukup dan murah.

Ketahanan aluminium terhadap korosi dapat ditingkatkan dengan proses anodizing sehingga dapat meningkatkan umur pakai. Anodizing adalah suatu proses pelapisan dengan menggunakan aluminium oksida pada permukaan aluminium (Al) dan paduannya (aluminium alloy) [1]. Aluminium oksida $\left(\mathrm{Al}_{2} \mathrm{O}_{3}\right)$ adalah hasil reaksi antara aluminium dengan oksigen dan merupakan lapisan tipis yang menutupi permukaan aluminium serta berfungsi untuk melindungi aluminium dari oksidasi lebih lanjut yang merupakan proses terjadinya korosi. Sehingga proses anodizing merupakan proses untuk menumbuhkan lapisan oksida di atas permukaan aluminium dengan menggunakan arus atau tegangan dengan besaran tertentu di dalam suatu larutan elektrolit.

Arus dan tegangan digunakan untuk membantu terjadinya reaksi kimia di dalam larutan elektrolit. Arus dan tegangan merupakan parameter yang sangat bepengaruh di dalam proses anodizing, semakin besar arus dan tegangan maka akan semakin tebal lapisan oksida yang terjadi di permukaan aluminium dan kekerasannya (hardness) juga akan meningkat [2].

Kuat arus, tegangan dan suhu merupakan faktor yang sangat penting dan sangat berpengaruh di dalam proses anodizing. Kuat arus listrik dan lamanya waktu pada proses anodizing berpengaruh terhadap kekerasan lapisan pada permukaan aluminium [3] .

Disamping arus dan tegangan yang besar, maka arus dan tegangan yang konstan merupakan pilihan yang terbaik karena kita dapat menghitung waktu siklus yang diperlukan untuk mencapai ketebalan lapisan aluminium oksida yang dinginkan. Oleh karena itu di dalam penelitian ini akan dilakukan optimasi arus dan tegangan pada alat anodizing portable untuk mendapatkan produk yang terbaik dengan melakukan beberapa pengukuran dan pengujian arus dan tegangan.

\section{METODOLOGI PENELITIAN}

Metodologi yang digunakan dalam menyusun penelitian tugas ini adalah sebagai berikut :

1. Pembuatan Rangkaian

Pada awal penelitian dilakukan pembuatan alat anodizing portable. Anodizing portable secara garis besar terdiri dari power supply, timer, kontainer, timbal sebgai katoda dan larutan elektrolit. Bentuk alat anodizing portable disesuaikan dengan Gambar.

2. Pengambilan Data

Pengambilan data dilakukan dengan menggunakan alat multimeter dan thermometer/alat pencatat suhu. Pada penelitian ini menggunakan dua variabel yaitu

a. Variabel arus: 2A, 3A, dan 4A dengan waktu anodizing selama 10 menit.

b. Variabel tegangan: $8 \mathrm{~V}, 9 \mathrm{~V}$ dan $10 \mathrm{~V}$ dengan waktu anodizing selama 10 menit.

3. Analisis data dan penarikan kesimpulan 
Setelah data didapatkan, maka akan dilakukan analisis. Dari hasil analisa data dan perbandingan metode yang dilakukan, dapat ditarik kesimpulan yang merupakan jawaban dari permasalahan.

\section{HASIL DAN PEMBAHASAN}

\subsection{Desain Portable Anodizing}

Penerapan teknologi yang akan dilakukan dalam penelitian ini adalah penggunaan teknologi hard anodizing yaitu teknik penumbuhan lapisan keras anodik oksida pada permukaan logam aluminium yang bersifat tahan karat, anti gores, dan hidrofobik. Teknologi ini telah banyak diaplikasikan pada bahan teknik yang digunakan pada kondisi lingkungan ekstrim meliputi aplikasi struktural, otomotif, industri pesawat, sepeda, dsb. Namun juga sudah mulai merambah peralatan sehari-hari seperti elektronik, alat olahraga, gadget, dsb. Bahan pelapis yang dihasilkan dari proses hard anodizing memiliki adhesi yang baik karena merupakan jenis conversion coating yang dapat melindungi permukaan logam dari proses karatan dan goresan.

Pada prinsipnya terdapat dua tingkatan anodizing berdasarkan besarnya tegangan atau arus yang dipakai dalam proses, yaitu konvensional anodizing dan hard anodizing. Konvensional anodizing yang biasanya menggunakan tegangan rendah sekitar $5-20 \mathrm{~V}$ menghasilkan lapisan oksida berpori yang tipis dalam order $\mathrm{nm}$ sampai beberapa mikrometer. Teknik ini biasanya digunakan untuk menghasilkan lapisan perantara sebelum finishing dengan cat. Pada Gambar 1. dapat dilihat rangkaian portable anodizing.

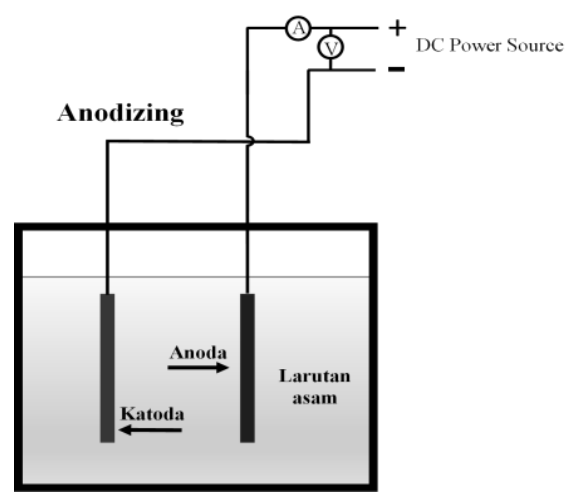

Gambar 1. Desain Portable Anodizing

Hard anodizing dilakukan pada tegangan lebih tinggi mendekati $\sim 100 \mathrm{~V}$ sehingga dihasilkan lapisan oksida yang padat dan lebih tebal dalam order puluhan mikrometer dan biasanya langsung digunakan tanpa adanya proses finishing tambahan. Lapisan oksida keras dapat menjadi alternatif pengganti dari teflon. Sedangkan pelapis bahan produk hard anodizing bersifat non toxic dan lebih tahan lama.

Peralatan dan bahan yang diperlukan untuk proses anodizing tergolong sederhana. Peralatan yang digunakan adalah power supply sebagai sumber, digital multimeter (DMM) data logger untuk mengukur arus/tegangan output, gelas beaker tempat elektrolit dan sampel diletakkan, dan magnetic stirrer untuk mengaduk larutan.

Peralatan anodizing tersebut diatas dapat dibuat lebih portable untuk skala home industry. Kontainer anodizing terdiri atas kotak stainless steel tebal dengan volume sekitar 
5 L. Katoda yang digunakan adalah stainless steel. Untuk sumber tegangan akan digunakan power supply dc $120 \mathrm{~V} / 1 \mathrm{~A}$. Larutan yang akan digunakan adalah $10 \%$ sodium hidroksida untuk pembersih dan $2 \mathrm{M}$ asam sulfat. Optimasi waktu anodizing akan dilakukan untuk mendapatkan ketebalan coating yang berbeda. Ketebalan coating diukur dengan coating thickness gauge.

\subsection{Pengujian Rangkaian Anodizing}

3.2..1. Perbandingan arus dan waktu.

- Variable arus yang digunakan adalah 2A, 3A, dan 4A dengan waktu anodizing selama 10 menit.

- Luas permukaan benda kerja adalah $50,24 \mathrm{~cm}^{2}$

Tabel 1. Arus Konstan

\begin{tabular}{|c|c|c|c|c|c|c|c|}
\hline \multicolumn{7}{|c|}{ Arus Konstan } \\
\hline No. & $\begin{array}{c}\text { Waktu } \\
(\text { detik) }\end{array}$ & $\begin{array}{c}\text { Arus } \\
(\mathbf{A})\end{array}$ & $\begin{array}{c}\text { Tegangan } \\
(\mathbf{V})\end{array}$ & $\begin{array}{c}\text { Arus } \\
(\mathbf{A})\end{array}$ & $\begin{array}{c}\text { Tegangan } \\
(\mathbf{V})\end{array}$ & $\begin{array}{c}\text { Arus } \\
(\mathbf{A})\end{array}$ & $\begin{array}{c}\text { Tegangan } \\
(\mathbf{V})\end{array}$ \\
\hline 1 & 0 & 2 & 7.7 & 3 & 8.6 & 4 & 10.5 \\
\hline 2 & 30 & 2 & 7.7 & 3 & 8.5 & 4 & 10.3 \\
\hline 3 & 60 & 2 & 7.7 & 3 & 8.6 & 4 & 9.7 \\
\hline 4 & 90 & 2 & 7.7 & 3 & 8.5 & 4 & 9.6 \\
\hline 5 & 120 & 2 & 7.7 & 3 & 8.4 & 4 & 9.4 \\
\hline 6 & 150 & 2 & 7.7 & 3 & 8.4 & 4 & 8.6 \\
\hline 7 & 180 & 2 & 7.7 & 3 & 8.3 & 4 & 8 \\
\hline 8 & 210 & 2 & 7.6 & 3 & 8.3 & 4 & 7.7 \\
\hline 9 & 240 & 2 & 7.6 & 3 & 8.2 & 4 & 7.6 \\
\hline 10 & 270 & 2 & 7.6 & 3 & 8.2 & 4 & 7.5 \\
\hline 11 & 300 & 2 & 7.6 & 3 & 8.3 & 4 & 7.2 \\
\hline 12 & 330 & 2 & 7.7 & 3 & 8.2 & 4 & 7.4 \\
\hline 13 & 360 & 2 & 7.7 & 3 & 8.2 & 4 & 7.4 \\
\hline 14 & 390 & 2 & 7.7 & 3 & 8.2 & 4 & 7.4 \\
\hline 15 & 420 & 2 & 7.7 & 3 & 8.2 & 4 & 7.5 \\
\hline 16 & 450 & 2 & 7.9 & 3 & 8.2 & 4 & 7.5 \\
\hline 17 & 480 & 2 & 7.9 & 3 & 8.2 & 4 & 7.3 \\
\hline 18 & 510 & 2 & 7.8 & 3 & 8.2 & 4 & 7.4 \\
\hline 19 & 540 & 2 & 7.9 & 3 & 8.2 & 4 & 7.5 \\
\hline 20 & 570 & 2 & 7.8 & 3 & 8.1 & 4 & 7.5 \\
\hline 21 & 600 & 2 & 7.8 & 3 & 8.1 & 4 & 7.4 \\
\hline
\end{tabular}

Pada Tabel 1. dapat dilihat bahwa dengan arus yang konstan maka tegangan yang dihasilkan tidak konstan atau mengalami naik turun yang kecil antara $0,1 \mathrm{~V}-0,2 \mathrm{~V}$ jika standar tegangan yang diambil adalah $7,7 \mathrm{~V}$. Naik turunnya tegangan terjadi karena percobaan ini dilakukan pada suhu ruangan sekitar $31-35^{\circ} \mathrm{C}$ sehingga tidak konstannya suhu sangat berpengaruh kepada teganan yang dihasilkan. Di dalam proses anodizing, suhu juga merupakan parameter yang sangat menentukan produk yang dihasilkan. Semakin rendah suhunya maka semakin baik aluminium oksida yang ditumbuhkan dan produk yang dihasilkan akan mempunyai permukaan yang halus serta lapisan aluminium oksida yang ditumbuhkan akan merata di seluruh permukaan aluminium. Pergerakan tegangan juga dapat dilihat pada gambar $2-4$ di bawah ini. 
Vol. 9, No. 2, Desember 2019, P-ISSN 2356-1505, E-ISSN 2656-9175

https://doi.org/10.33322/sutet.v9i2.525

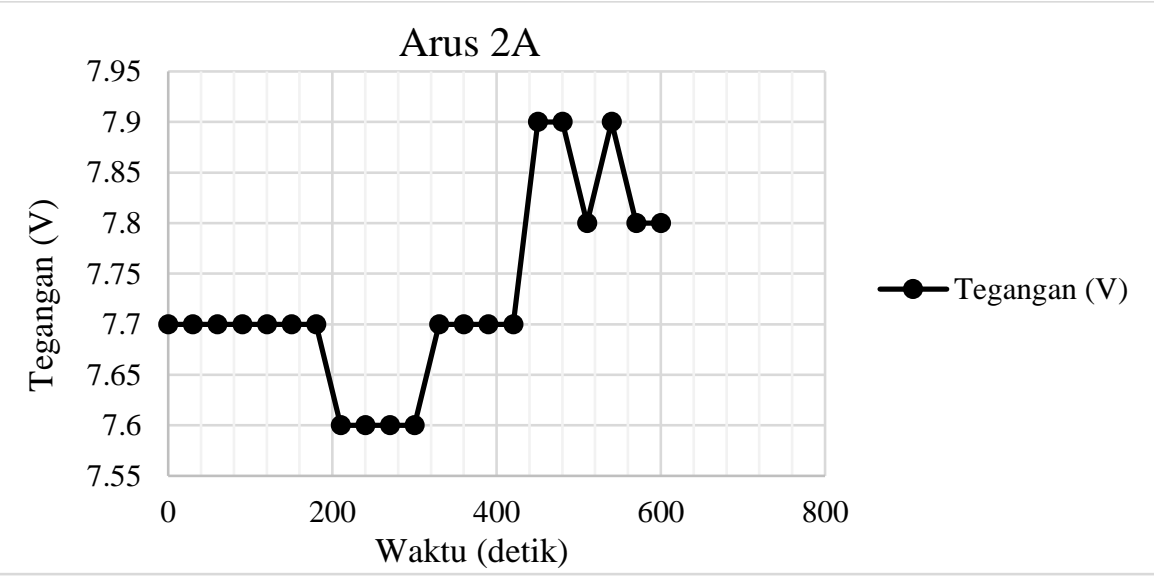

Gambar 2. Arus $2 \mathrm{~A}$

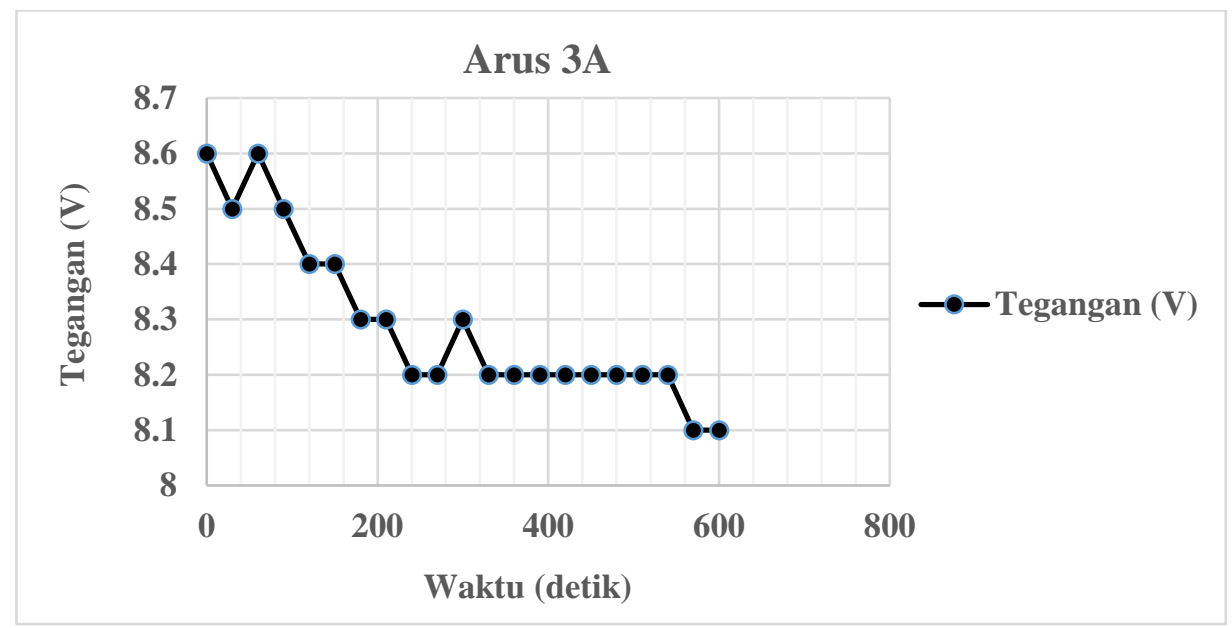

Gambar 3. Arus 3A

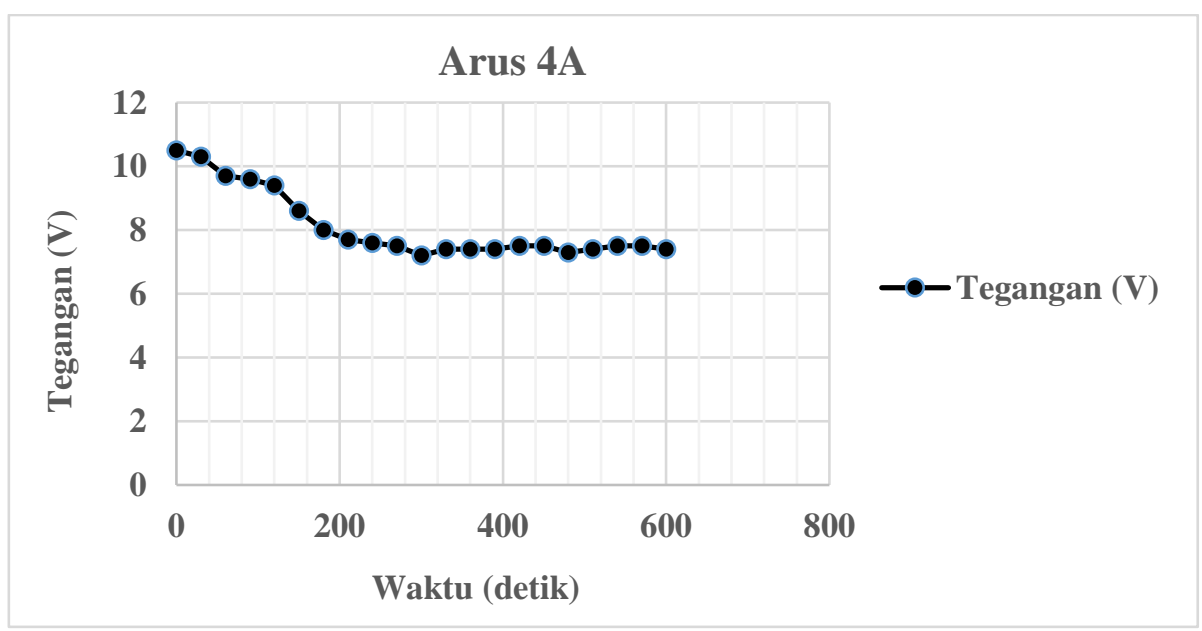

Gambar 4. Arus 4A

3.2..2. Perbandingan tegangan dan waktu.

- Variable tegangan: 8V, 9V dan 10V dengan waktu anodizing selama 10 menit.

- Luas permukaan benda kerja adalah $50,24 \mathrm{~cm}$ 
Tabel 2. Tegangan Konstan

\begin{tabular}{|c|c|c|c|c|c|c|c|}
\hline \multicolumn{7}{|c|}{ Tegangan Konstan } \\
\hline No. & $\begin{array}{c}\text { Waktu } \\
(\text { detik) }\end{array}$ & $\begin{array}{c}\text { Arus } \\
(\mathbf{A})\end{array}$ & $\begin{array}{c}\text { Tegangan } \\
(\mathbf{V})\end{array}$ & $\begin{array}{c}\text { Arus } \\
(\mathbf{A})\end{array}$ & $\begin{array}{c}\text { Tegangan } \\
(\mathbf{V})\end{array}$ & $\begin{array}{c}\text { Arus } \\
(\mathbf{A})\end{array}$ & $\begin{array}{c}\text { Tegangan } \\
(\mathbf{V})\end{array}$ \\
\hline 1 & 0 & 3 & 8 & 3.56 & 9 & 5.16 & 10 \\
\hline 2 & 30 & 3.05 & 8 & 3.57 & 9 & 5.17 & 10 \\
\hline 3 & 60 & 3.15 & 8 & 3.58 & 9 & 5.18 & 10 \\
\hline 4 & 90 & 3.17 & 8 & 3.62 & 9 & 5.18 & 10 \\
\hline 5 & 120 & 3.2 & 8 & 3.62 & 9 & 5.2 & 10 \\
\hline 6 & 150 & 3.2 & 8 & 3.67 & 9 & 5.18 & 10 \\
\hline 7 & 180 & 3.21 & 8 & 3.67 & 9 & 5.18 & 10 \\
\hline 8 & 210 & 3.2 & 8 & 3.69 & 9 & 5.18 & 10 \\
\hline 9 & 240 & 3.23 & 8 & 3.67 & 9 & 5.18 & 10 \\
\hline 10 & 270 & 3.24 & 8 & 3.69 & 9 & 5.18 & 10 \\
\hline 11 & 300 & 3.23 & 8 & 3.65 & 9 & 5.18 & 10 \\
\hline 12 & 330 & 3.22 & 8 & 3.66 & 9 & 5.2 & 10 \\
\hline 13 & 360 & 3.23 & 8 & 3.69 & 9 & 5.18 & 10 \\
\hline 14 & 390 & 3.21 & 8 & 3.67 & 9 & 5.19 & 10 \\
\hline 15 & 420 & 3.22 & 8 & 3.69 & 9 & 5.19 & 10 \\
\hline 16 & 450 & 3.21 & 8 & 3.67 & 9 & 5.18 & 10 \\
\hline 17 & 480 & 3.2 & 8 & 3.69 & 9 & 5.19 & 10 \\
\hline 18 & 510 & 3.21 & 8 & 3.69 & 9 & 5.18 & 10 \\
\hline 19 & 540 & 3.19 & 8 & 3.67 & 9 & 5.18 & 10 \\
\hline 20 & 570 & 3.19 & 8 & 3.69 & 9 & 5.18 & 10 \\
\hline 21 & 600 & 3.19 & 8 & 3.69 & 9 & 5.18 & 10 \\
\hline
\end{tabular}

Pada Tabel 2. Dapat dilihat bahwa ketika diberikan arus ke dalam rangkaian anodizing maka dibutuhkan waktu sampai proses anodizing berjalan. Pada percobaan ini waktu yang dibutuhkan sampai proses anodizing berjalan sekitar $90-100$ detik. Proses anodizing berjalan sampai benda kerja mempunyai ketebalan oksida maksimal dan arus akan mengalami penurunan atau konstan seperti terlihat pada gambar 5 dan gambar 7 . Sedangkan pada gambar 6 , arus proses anodizing masih berjalan sehingga arus tidak mengalami penurunan hal itu dapat terjadi karena waktu yang digunakan pada percobaan ini adalah 10 menit atau 600 detik sedangkan proses anodizing dan ketebalan oksida pada benda kerja belum maksimal.

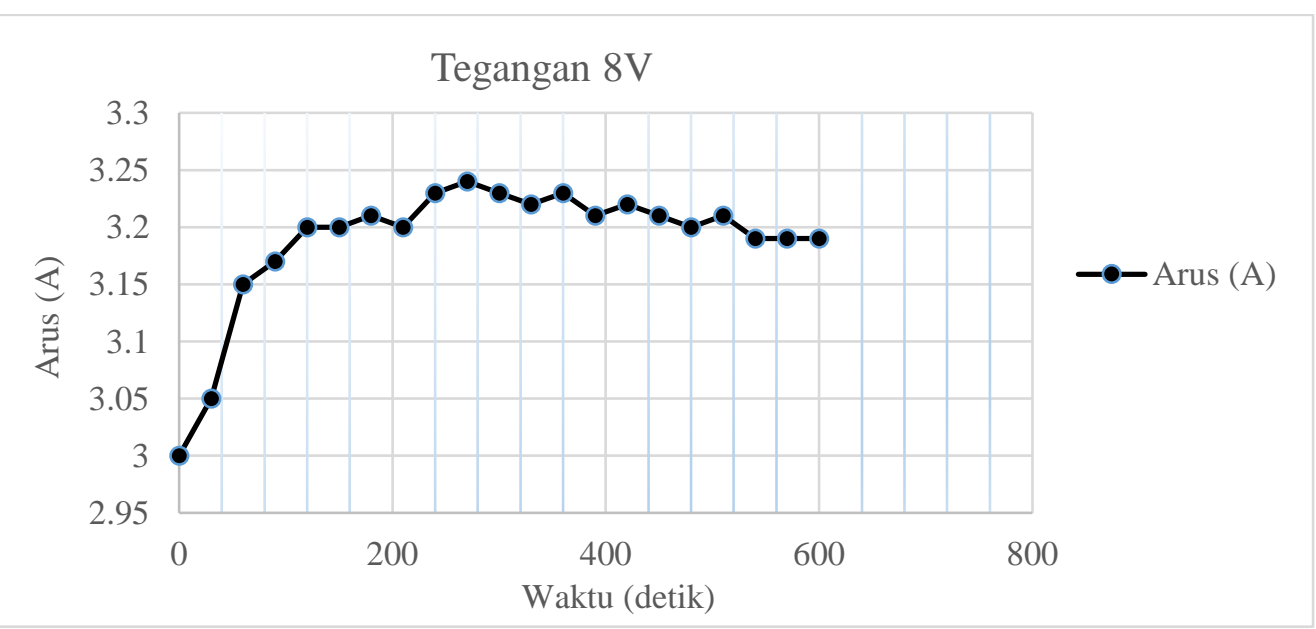

Gambar 5. Tegangan 8V 


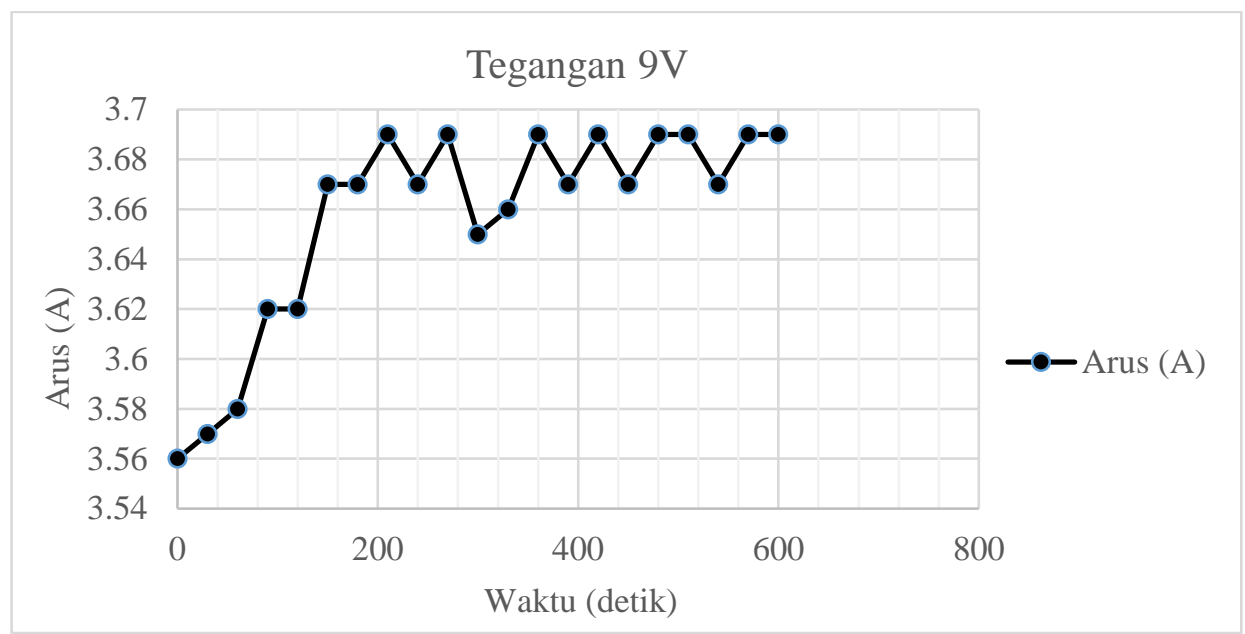

Gambar 6. Tegangan 9V

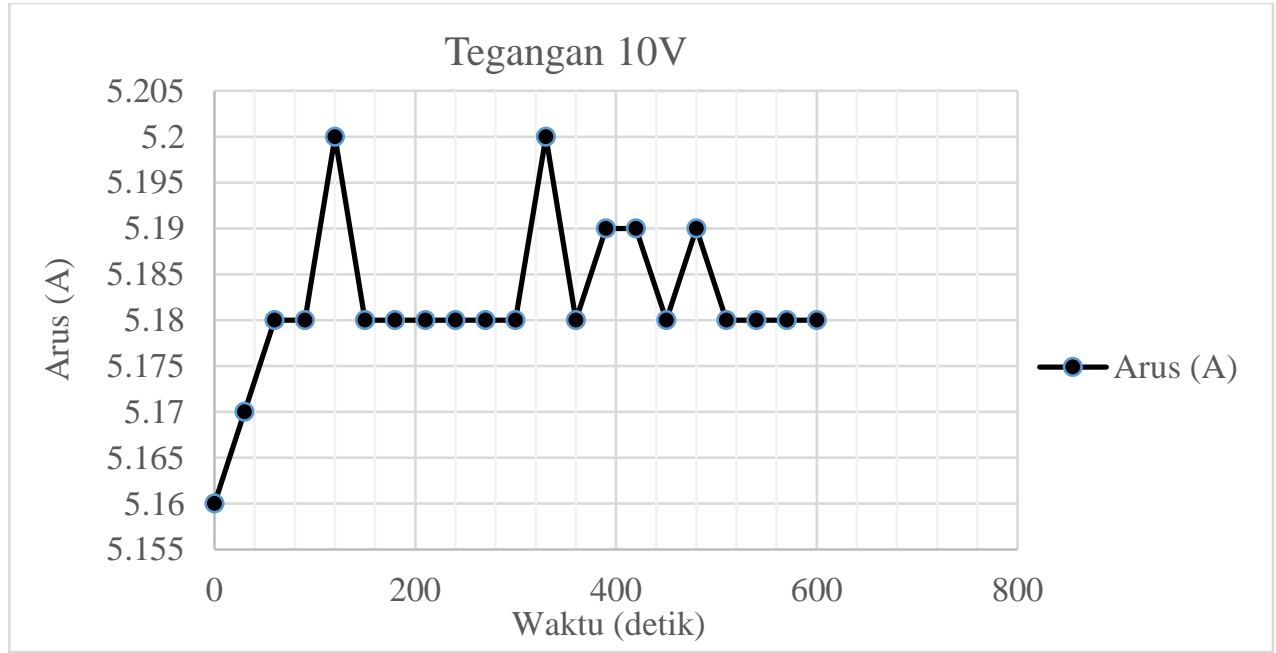

Gambar 7. Tegangan 10V

\section{KESIMPULAN DAN SARAN}

\subsection{Kesimpulan}

Alat Anodizing Portable ini dapat digunakan oleh banyak orang dengan berbagai latar belakang dan di berbagai lokasi. Pada percobaan ini tegangan dan arus yang digunakan pada proses anodizing ini dapat diatur sesuai dengan kebutuhan. Hal lain yang dapat disimpulkan adalah kuat arus listrik anodizing yang semakin besar maka hasil nilai kekerasan nya akan semakin meningkat dan lapisan alumunium oksida yang dihasilkan akan semakin besar. Sedangkan pengaturan suhu pada proses anodizing ternyata sangat berpengaruh kepada lapisan alumunium oksida pada benda kerja.

\subsection{Saran}

Penelitian ini dapat dikembangkan pada beberapa wilayah. Pengaturan tegangan, arus dan suhu pada Alat Anodizing Portable yang lebih optimal disarankan lebih banyak mendapat perhatian dalam pengembangan Alat Anodizing Portable ini. 


\section{UCAPAN TERIMAKASIH}

Penulis mengucapkan terima kasih kepada Departemen Elektro, Porgram Studi Teknik Elektro, Sekolah Tinggi Teknin PLN, yang telah memberi dukungan yang membantu pelaksanaan penelitian dan penulisan artikel.

\section{DAFTAR PUSTAKA}

[1] J. Milton F. Stevenson, Anodizing, ASM Handbook, Volume 5: Surface Engineering, 1994.

[2] N. M. d. C. P. Hanung Hermawan, "PENGARUH KUAT ARUS PADA PROSES ANODIZING TERHADAP KARAKTERISTIK VELG MOBIL MERK BSA," Journal of Mechanical Engineering, Universitas Tidar., vol. Vol.1 No.1 (2017), pp. 34-40, 2017.

[3] N. N. Santhiarsa, "Pengaruh Kuat Arus Listrik dan Waktu Proses Hard Anodizing Pada Aluminium Terhadap Kekerasan dan Ketebalan Lapisan," Jurnal Ilmiah, Teknik Mesin Universitas Udayana, 2009. 